\title{
Serás ministro: uma proposta de leitura do texto literário
}

\author{
Marise Rodrigues Guedes \\ Instituto Federal de Educação, Ciência e Tecnologia Baiano - IF Baiano
}

\begin{abstract}
Resumo
Este artigo objetiva apresentar uma proposta pedagógica de leitura da crônica literária Serás Ministro, de Carlos Drummond de Andrade. Para embasar esta prática, serão utilizados os pressupostos teóricos de Fernandes (2001) e Mello (2010) que apontam para a necessidade do desenvolvimento de estratégias e de ampliação do universo leitor do aluno através de materiais didáticos que contemplem a leitura eficaz do texto literário; os estudos de Meurer (1999), que tratam das relações dialéticas entre literatura e sociedade; além das contribuições de Solé (1998) e das recomendações dos Parâmetros Curriculares Nacionais (1998), que tratam acerca de leitura crítica e apontam caminhos possíveis para a experienciação da leitura de textos literários em sala de aula.

Palavras-chave: Carlos Drummond de Andrade; Literatura; Ensino; Língua Portuguesa.
\end{abstract}

\begin{abstract}
This article aims to present a pedagogical proposal for reading the literary chronicle Serás Ministro, by Carlos Drummond de Andrade. To this end, the study will use various theoretical assumptions: Fernandes (2001) and Mello (2010), who point to the need to develop strategies and to broaden the reader's universe through didactic materials that contemplate the effective reading of the literary text; the studies of Meurer (1999) that deal with the dialectical relations between literature and society; the contributions of Solé (1998). The recommendations of the Parâmetros Curriculares Nacionais (1998) will also be used, as they deal with critical reading and point to possible ways of experiencing the reading of literary texts in the classroom.

Keywords: Carlos Drummond de Andrade; Literature; Teaching; Portuguese Language.
\end{abstract}

\section{A LEITURA E O TEXTO LITERÁRIO NAS AULAS DE LÍNGUA PORTUGUESA}

As práticas pedagógicas em sala de aula deixam subjacentes os conceitos de leitura, literatura e, consequentemente, de texto literário, adotados pelos professores no trabalho com os seus alunos. Das concepções mais frequentes, tem-se a leitura como decodificação de palavras, busca de significados isolados e fluência na leitura. Nesse caso, o bom leitor é aquele que não interrompe a sua leitura, que sabe decifrar exatamente o código que está lendo. Também nessa vertente, a literatura, bem como o texto literário, surge como pretexto para o trabalho com a leitura, sendo apenas ponto de partida para o contato com palavras difíceis e 
para atividades que requerem mais o conhecimento da língua enquanto um sistema abstrato que como um produto de diálogos constantes entre o indivíduo e a sociedade. Não se pode esperar que de um universo limitador como o que expusemos acima, venha a formar-se algum leitor.

Além disso, pesquisas apontam os descaminhos que a leitura do texto literário vem percorrendo em sala de aula, através da análise de livros didáticos. Esse material, como é sabido, é o principal recurso utilizado pelos professores e, muitas vezes, é o único ao seu alcance. Os estudos apontam a necessidade de se propor efetivamente a leitura do texto literário, em detrimento de sua utilização como forma, apenas, ou com outros objetivos quaisquer que limitam e subestimam a capacidade leitora dos estudantes. De maneira geral, tais estudos constataram que as abordagens realizadas pelos livros didáticos não atendem às necessidades do texto literário, que requerem "um tratamento específico, diferente daquele que se dá aos demais textos do livro didático [...]” (FERNANDES, 2001, p. 171).

Diante dessa perspectiva, é pertinente apresentar não um modelo, mas um modesto caminho para a experienciação de uma obra literária em sala de aula, uma vez que é dever da escola promover o contato do aluno com o texto literário. Além do mais, muitas vezes, esse espaço é o único onde o aluno pode vivenciar a leitura literária. No entanto, tencionamos que o contato promovido em sala de aula não seja o contato por ele mesmo, como já se faz nas salas de aula por aí a fora, mas que permita ao aluno posicionar-se frente ao texto como um leitor crítico, entendedor da literatura como arte capaz de ampliar o seu olhar diante da sociedade em que vive.

Com este intuito, o propósito maior deste trabalho é apresentar uma proposta pedagógica para a efetiva leitura de textos literários na escola. Tal proposta será desenvolvida a partir da crônica literária Serás Ministro, de Carlos Drummond de Andrade, baseada nas contribuições de Solé (1998), Fernandes (2001), Meurer (2000), Melo (2010), entre outros.

\section{CAMINHOS PARA O TRABALHO COM O TEXTO LITERÁRIO EM SALA DE AULA}

As práticas de linguagem realizadas pelos homens são realizadas a partir de gêneros textuais, o que torna imprescindível que estas práticas sejam mediadas por eles, sobretudo nas aulas de Língua Portuguesa. Sobre este quesito, os Parâmetros Curriculares Nacionais - PCNs (1998) apontam alguns gêneros como os mais adequados para o trabalho no Ensino Fundamental II, tais como o texto dramático, o conto, o cordel, a crônica, a notícia, a 
entrevista, entre outros. Como neste trabalho trataremos mais especificamente sobre a crônica, falemos um pouco a respeito deste gênero textual.

Do grego chrónos, crônica é um gênero literário que possuiu atribuições distintas ao longo dos tempos. Apesar de já no século XII apresentar-se como uma visão individual da história, sua característica principal era narrar fatos em ordem cronológica, o que era denominado cronições, posteriormente substituído por história. As relações da crônica com o tempo - chrónos - se dão à medida que ela recorta um momento no tempo e dele faz um registro poético, geralmente com traços de humor. O caráter de divertimento da crônica, porém, pode trazer implícita uma crítica à realidade.

Como afirma Soares (2007, p. 65), “conscientemente fragmentária (e essa é a sua força), pois não pretende captar a totalidade dos fatos, a crônica vem se impondo nos quadros da literatura brasileira [...]", como nas obras de Machado de Assis, Carlos Drummond de Andrade, Millôr Fernandes, Rubem Braga, entre outros.

Assim, a crônica eterniza os momentos simples do dia a dia poeticamente, com pitadas de humor e de crítica em narrativas, geralmente, curtas. Contudo, sua brevidade não é limitadora; ao contrário, da recriação possível através da arte literária, o cronista ao ir além do fato, permite uma leitura mais abrangente, denotando ângulos talvez não observados através da simples observação de um fato.

Nesse contexto, a literatura se constitui como a oportunidade que o aluno encontra de ampliar os seus modos de ler, sobretudo pelo caráter cultural e estético que os textos literários possuem. No entanto, para que a recepção do texto literário se dê de forma satisfatória, são requeridos leitores críticos, que superem as dificuldades e que encontrem no texto pistas capazes de guiá-los, de sustentar o seu posicionamento sobre aquela leitura e de refletir, a partir dela, sobre o mundo em que vive, percebendo a "relação dialética existente entre linguagem e práticas sociais" (MEURER, 2000, p.160).

$\mathrm{Na}$ recepção crítica de um texto, estão envolvidos tanto elementos semânticos, quanto elementos históricos, conforme sinalizado por Meurer (2000). Com esses elementos, o aluno poderá compreender o funcionamento do texto literário e avançar " [...] da leitura mais ingênua que trate o texto como mera transposição do mundo natural para a leitura mais cultural e estética, que reconheça o caráter ficcional e a natureza cultural da literatura" (BRASIL, 1998, p.71).

Outros objetivos para a formação do leitor são elencados pelos PCNs, dentre os quais podemos destacar o desenvolvimento da capacidade de construir expectativas sobre o texto, tendo em vista os conhecimentos que já possui, "confirmando antecipações e inferências 
realizadas antes e durante a leitura; articulando o maior número possível de índices textuais e contextuais na construção do sentido do texto" (BRASIL, 1998, p. 50).

Sobre este aspecto, Solé (1998) aponta alguns caminhos que podem ser utilizados no trabalho com a leitura de textos, inclusive os literários, em sala de aula. A autora ressalta que antes de se iniciar qualquer leitura, deve-se motivar o leitor para a leitura que ele vai realizar. Isso pode ser feito de diversas formas, seja através de uma simples conversa sobre as expectativas do leitor sobre o texto, seja com outros tipos de texto que de certa forma remetam ao conteúdo do texto principal, no nosso caso, o texto literário.

Outro ponto importante para a motivação para a leitura é manter o leitor esclarecido sobre os objetivos que pretende alcançar com a leitura. Assim, o estabelecimento de objetivos é um passo decisivo para a realização da leitura de um texto. A autora afirma que os objetivos para a leitura podem ser vários, dentre os quais encontramos ler para buscar informações específicas, ler para comunicar um texto a um auditório, ler para aprender, ler por prazer. Para este último objetivo de leitura, a autora aponta o texto literário como o "tipo de texto ideal para experimentar o prazer de ler [...]" (SOLÉ, 1998, p. 100).

O conhecimento sobre o gênero textual a ser lido também é importante para o exercício antes da leitura, uma vez que, tendo ideia do que seja esse gênero, o aluno pode já imaginar o que poderá ser o objeto de sua leitura, pois o posicionamento frente à leitura de uma notícia não será o mesmo frente à leitura de uma crônica. Conforme Mello (2010, p.42), “[...] a compreensão dos gêneros e modos leva a uma maior compreensão dos procedimentos literários, como por exemplo, categorias genológicas, tais como espaço, tempo, personagem, etc., e se traduz em facilidade na interpretação da obra."

Além disso, a realização de previsões sobre o texto, ou seja, incitar os alunos a realizarem antecipações ao que se vai ler, permite a ativação dos conhecimentos prévios que possuem, ativando o seu horizonte de expectativas em relação ao texto. Vale ressaltar que previsões são apenas previsões e, se o texto literário é polissêmico, plurissignificativo, as previsões podem ou não encontrar equivalência no texto que os alunos ainda vão ler. Então, é atribuição do professor a orientação no processo de ensino-aprendizagem.

Para uma leitura eficaz do texto, várias estratégias podem ser utilizadas durante a leitura, como, por exemplo, a leitura compartilhada e dramatizada. Com essas estratégias, o professor desloca o aluno de uma zona de conforto e coloca-o como também responsável pelo processo de produção de sentido do texto, conforme Solé (1998). Além disso, esses tipos de leitura podem auxiliar os leitores menos atentos a preencherem os vazios de significação do texto que não conseguiram com a leitura individual. 
Evitar interrupções durante a leitura também é um procedimento eficaz para a atividade de um leitor ativo. Assim, o aluno deve ser educado a utilizar as pistas que o texto lhe proporciona para a compreensão de uma palavra desconhecida e a se autocorrigir, pois ao interromper a leitura, ele desliga. O uso de dicionários, glossário, consulta ao colega ou ao professor não são procedimentos descartáveis, mas estratégias que podem ser utilizadas: em segundo plano. Assim, "quem compreende o que está lendo, acabará entendendo as palavras" (SOLÉ, 1998, p. 128).

Como estratégias para depois da leitura, Solé (1998) aponta, entre outras, a elaboração de resumo. Realizado de maneira escrita ou oralmente, a utilização do resumo permite que o aluno retome o texto lido e, a partir de então, possa perceber em quais momentos do texto não se chegou à compreensão necessária, podendo alcançá-la.

A construção dos significados de um texto não é tarefa fácil, no entanto, é possível e necessário ensinar a compreender. No entanto, principalmente em se tratando do texto literário, não se pode esperar respostas unívocas seja numa classe de poucos ou de trinta alunos, tendo em vista que as experiências vivenciadas por cada um se somarão ao texto, na produção do seu sentido. Deve-se, portanto, atentar a esta pluralidade de significados que podem ser atingidos a partir das estratégias elencadas por Solé (1998), cuidando, é claro, da coerência das respostas em relação a um texto que, por si, não é uno.

Considerando, ainda, o que nos ensina Fernandes (2001, p. 167), ao afirmar que "textos literários deveriam ser entremeados com os de outra natureza, como textos de jornal, cartas, revistas, textos técnicos, letras de música e textos recolhidos da tradição oral, entre outros”, a seguir propomos uma possível prática de leitura para a crônica Serás Ministro, de Carlos Drummond de Andrade.

\section{UMA PROPOSTA DE LEITURA LITERÁRIA DA CRÔNICA SERÁS MINISTRO, DE CARLOS DRUMMOND DE ANDRADE}

Esta proposta volta-se a alunos do $8^{\circ}$ ou $9^{\circ}$ ano do Ensino Fundamental II e possui como objetivo geral desenvolver a leitura crítica a partir da crônica literária Serás Ministro, de Carlos Drummond de Andrade. Para atingir este propósito maior, traçamos os seguintes objetivos específicos: (re)conhecer características da crônica literária; proporcionar o contato com o texto literário; permitir o diálogo sobre a convivência em sociedade, bem como suas convenções e valores; proporcionar a reflexão acerca das relações humanas; compreender o 
texto literário como produto da interação leitor-texto-autor; perceber a atividade de leitura como uma prática social; e incentivar o contato com outros textos literários.

Para o completo desenvolvimento desta proposta, são necessárias seis aulas de cinquenta minutos cada. Como, geralmente, aulas de Língua Portuguesa são geminadas, as orientações que seguem estão organizadas em pares de aulas, mas, a depender do contexto em que seja aplicada, pode haver uma redistribuição. Vale salientar que os textos e vídeos utilizados aqui estão disponíveis na internet, através dos links informados nas referências.

Aulas 01 e 02: para início de conversa, o professor deve informar aos alunos que lerão uma crônica de Carlos Drummond de Andrade e apresentá-los aos objetivos que pretende alcançar, prestando os esclarecimentos necessários.

Após ter conversado com os alunos sobre os objetivos propostos, deverá começar a discussão perguntando aos alunos se eles sabem o que é crônica. À medida que ouve as respostas, o professor deverá ir anotando-as na lousa, construindo uma chuva de ideias sobre a palavra e o gênero. Em seguida, caso ainda não seja de conhecimento dos alunos, o professor deverá informá-los de que a palavra crônica deriva do grego chrónos e perguntar-lhes o significado desta palavra. Neste momento, poderá ser distribuir cópias do texto Deus Cronos e pedir aos alunos que façam a leitura, para que conheçam a história de Cronos. Depois dessa leitura, os alunos deverão fazer comentários sobre o texto, tentando estabelecer relações entre a palavra crônica e o deus grego Cronos. Para finalizar este momento, os alunos assistirão ao vídeo Documentário confronto dos deuses (do minuto 5'34” ao 8’32”). Então, o professor utilizará das respostas dos alunos para construir o conceito de crônica, destacando o seu caráter literário e a sua peculiaridade em perenizar o momento.

Após a concluir a discussão, os alunos serão encaminhados ao laboratório de informática da escola, local onde deverá ocorrer esta segunda aula. O professor deverá informá-los de que eles lerão uma crônica cujo título é Serás Ministro, do escritor brasileiro Carlos Drummond de Andrade. Antes de permitir o acesso a este texto, os alunos utilizarão a internet para fazer uma pesquisa que deverá responder aos seguintes questionamentos: 1 . Quem é e o que faz um Ministro? 2. Pesquise o nome e a função de um Ministro brasileiro. O professor poderá sugerir um site no qual os alunos possam descobrir os nomes dos ministros brasileiros, bem como as responsabilidades de cada um. Caso não seja possível o acesso à internet na escola, o professor poderá imprimir o material do site e disponibilizar aos alunos através de impressão, projetando pelo Datashow, da televisão ou outro meio disponível.

Após a pesquisa, os alunos deverão responder oralmente às questões propostas, momento em que o professor pode dar os esclarecimentos necessários. 
Aulas 03 e 04: nestas aulas, o professor deverá fazer uma breve recapitulação sobre o que foi discutido nas aulas 01 e 02. Para isso, sugerimos que escreva o nome da crônica Serás Ministro na lousa. O professor poderá perguntar aos alunos sobre o assunto da crônica, os personagens, entre outros. São questionamentos possíveis, por exemplo: Quem é mesmo este que será ministro? Por que alguém quer que ele seja ministro? Você conhece alguém que se chame Ministro ou que tenha um outro nome exótico? Você sabe qual é a história do seu nome? Acredita que o nome tem a ver com a pessoa? Estas questões servirão para criar uma ambientação às discussões posteriores e uma aproximação dos alunos ao texto, mesmo antes de o lerem.

Após os alunos realizarem as previsões a partir do título da crônica, o professor deverá distribuir uma cópia do texto Serás ministro para cada aluno e pedir que realizem uma leitura silenciosa.

Após esta primeira leitura, que proporcionará o reconhecimento do texto, o professor solicitará que onze alunos voluntários realizem a leitura dramatizada do texto. Para isso, eles precisarão inicialmente reconhecer a presença de diversos personagens no texto e, sem seguida, identificarão no texto as falas dos seus respectivos personagens, a saber: narrador, pai, mãe, Sr. Ministro, padre, escrivão do cartório, deputado, funcionário I, funcionário II e assessor.

Tendo realizado a leitura, a discussão será aberta com os seguintes questionamentos: 1. O texto se desenrola a partir de dois conflitos principais. Que conflitos são esses e porque eles ocorrem? 2. O pai e o Sr. Ministro trabalham no mesmo local, no entanto, possuem atribuições diferentes. O que faz cada um deles? O que essas funções representam na sociedade? 3. No texto, a mãe fala sobre pessoas importantes. Esta importância é sentimental? Por quê? 4. Ao encaminhar o batismo do filho, Tonzinho - o pai - decide convidar o $S r$. Ministro para batizar Ministro. Por que a mãe não concorda? Como o pai tenta convencê-la? Por que o pai quer que o Sr. Ministro batize o seu filho? 5. O pai afirma que o Sr. Ministro o trata de "igual pra igual". Esta afirmação é confirmada? Justifique.

Ao passo que os alunos vão respondendo, o professor vai esquematizando as colocações destes na lousa, de modo que eles possam visualizar que estão construindo juntos, os sentidos do texto que leram.

Após a discussão oral, o professor deverá entregar as seguintes questões impressas em uma folha para que cada aluno responda individualmente. Caso não seja possível imprimir, o professor poderá passar as questões no quadro e pedir que os alunos copiem e respondam isso demandará mais tempo: 1. Ministro nasce, cresce e vai trabalhar na mesma repartição que 
o pai, exercendo, inclusive, a mesma função. Como era o trabalho de Ministro? 2. Após algum tempo de trabalho, Ministro é promovido a contínuo. Numa empresa ou repartição, contínuo é o funcionário que realiza pequenos serviços. No texto, a utilização desta palavra tem um significado bastante peculiar. Que significado é este? Tente responder relacionando esta palavra ao trabalho que fora exercido pelo pai e agora é exercido pelo filho. 3 . Ao ser promovido a contínuo, Ministro vai trabalhar no gabinete do Sr. Ministro. O que acontece neste momento? 4. Releia o trecho que segue: "—-Este Ministro é um cretino! Me fez esperar uma hora nesta poltrona! — Perdão, Deputado, o senhor está ofendendo o Sr. Ministro! Eu? Eu? Estou me referindo a esse animal, esse... Até que se apurasse que o animal era Ministro, o contínuo - que confusão!” 5. Ao se referir a Ministro através das palavras "cretino" e "animal", o deputado deixa claro que a sua forma de tratar os outros varia de pessoa para pessoa. O que provoca esta diferenciação? O que ela significa? 6. O Sr Ministro, com os poderes que lhe são atribuídos pela sociedade, toma uma atitude para acabar com as confusões no seu gabinete: manda o Ministro "para uma vaga repartição de vago departamento". Relacione as palavras vaga e vago ao valor social do trabalho de Ministro dentro do gabinete. 7. Descontente com a sua situação, Ministro queixa-se ao pai. Ao que este lhe responde: "Ora, meu filho, hoje no bueiro, amanha no Pão de Açúcar." Pergunta-se: O desejo inicial do pai foi realizado? Por quê? Quais as relações do nome de Ministro com o valor social do cargo de Ministro de Estado?

Aulas 5 e 6: antes de iniciar as discussões sobre as respostas dadas às questões propostas nas aulas 3 e 4, o professor deverá solicitar que os alunos façam um breve resumo da história. Este momento pode ser realizado pedindo a algum aluno que conte com as próprias palavras como começa a história do texto Serás Ministro e, num determinado momento, pedir que outros alunos continuem, até que todos recapitulem o que fora lido na aula anterior.

Feito isto, o professor deverá construir coletivamente as respostas, sempre dando espaço para que o aluno fale. Este será um momento muito importante para consolidar a mensagem do texto. A discussão poderá finalizar com a seguinte provocação, que deverá ser escrita na lousa: o que mais vale em nossa sociedade: a pessoa ou o cargo que ela ocupa? Aqui, ainda, o professor deverá informar aos alunos que eles lerão a entrevista $E$ se eu fosse gari?, realizada pelo jornal Diário de São Paulo com o psicólogo social Fernando Braga, que queria provar a existência da Invisibilidade Pública (DELPHINO, 2017). Antes da leitura da entrevista, o professor provocará a reflexão dos alunos, a partir dos seguintes pontos: 1. Como a profissão de gari é vista pela sociedade brasileira? 2. Para você, o que quer dizer 
invisibilidade pública? Após a discussão destes dois pontos, o professor realizará a leitura compartilhada da entrevista $E$ se eu fosse gari?

Terminada a leitura, o professor deverá nortear uma discussão a partir de perguntas como: 1. De acordo com a entrevista lida, o que é invisibilidade pública? 2. Quais as relações entre a Invisibilidade Pública vivida pelo psicólogo-gari e a crônica Serás Ministro, de Drummond?

O professor deverá utilizar este momento para discutir com os alunos sobre o valor de cada pessoa. Poderá inclusive, trazer a discussão para dentro da escola, comentando sobre a importância de cada funcionário que ali está e questionando os alunos sobre o posicionamento deles a respeito do valor das pessoas. Encaminhando para o desfecho das discussões, mas não das reflexões, todos assistirão ao vídeo $O$ valor de cada um, baseado no conto $O$ carregador de águas.

Para finalizar, o professor pedirá aos alunos que comentem sobre as atividades realizadas a respeito da crônica, seus pontos fracos e fortes. Em seguida, incentivará que os alunos busquem outros textos de Carlos Drummond, Luís Fernando Veríssimo, Rubem Alves na biblioteca, na internet, para que leiam, reflitam e/ou divirtam-se.

\section{CONSIDERAÇÕES FINAIS}

A proposta desse trabalho foi promover uma reflexão sobre o ensino de literatura na escola, além de apresentar uma contribuição para práticas de leitura do texto literário em sala de aula, através da sequência didática aqui exposta. Ao tecermos considerações sobre como a literatura é trabalhada em sala de aula, em muitos casos somente por meio do livro didático, percebeu-se que os textos literários necessitam de um tratamento mais apurado.

Ratificamos, portanto, a importância de que o trabalho com o texto literário tenha objetivos definidos e que sejam adotadas estratégias para antes, durante e depois da leitura que facilitem a compreensão do texto, a construção de sentidos, bem como as relações estabelecidas no diálogo entre literatura e sociedade.

O trabalho com textos literários na escola também deve ser prazeroso e a interação dos alunos, por meio de questionamentos ao texto, é essencial para o envolvimento desses no processo de pluralidade de sentidos que a obra literária pode oferecer. Nesse sentido, trabalhar tendo como ponto de partida os gêneros textuais como a crônica, por exemplo, pode ser um caminho para aproximar o real do subjetivo. 
Cabe à escola e ao professor garantir que o aluno tenha acesso à obra literária, em vez de dar lugar apenas a fragmentos que, inclusive, podem acarretar sérios prejuízos à coesão, à coerência e à experiência estética dos textos. Além disso, tornar o trabalho com literatura uma prática constante nas aulas de Língua portuguesa é um grande desafio, mas de extrema relevância para a formação de leitores.

Sabemos que a proposta de leitura do texto literário aqui apresentada não esgota as possibilidades de abordagens para a literatura em aulas de Português. No entanto, tencionamos que ela possa trazer contribuições para estudantes e educadores nas salas de aula da Educação Básica.

\section{REFERÊNCIAS}

ANDRADE, Carlos Drummond. Serás Ministro. Disponível em http://versoeconversa.blogspot.com.br/2012/10/carlos-drummond-de-andrade-seras.html, acesso em 16 de junho de 2014.

BRASIL. Secretaria de Educação Fundamental. Parâmetros curriculares nacionais: terceiro e quarto ciclos do ensino fundamental: introdução aos parâmetros curriculares nacionais / Secretaria de Educação Fundamental. - Brasília : MEC/SEF, 1998.

DEUS CRONOS. Disponível em:

$<$ http://www.educ.fc.ul.pt/docentes/opombo/cinema/dossier/shine/deus_cronos.htm>, acesso em 16 de junho de 2017.

DOCUMENTÁRIO CONFRONTO DOS DEUSES. Disponível em:

$<$ http://www.youtube.com/watch?v=5TPU-sfuXxM\&src_vid=ut020I9k-

zw\&feature=iv\&annotation_id=annotation_1468996671>, acesso em 16 de junho de 2017.

DELPHINO, Plínio. E se eu fosse gari. Disponível em

http://www.ip.usp.br/imprensa/midia/2008/orq_cuiaba_7-12-2008.htm, acesso em 16 de junho de 2017.

FERNANDES, Maria Lúcia Outeiro. O texto literário no livro didático. Araraquara: Itinerários, 2001. p. 165-177

MELLO, Claudio José de Almeida. Leitura e ensino de literatura: análise de livros didáticos. Disponível Em

http://www.revistavoos.com.br/seer/index.php/voos/rticle/view/80/03_Vol2_VOOS2010_CL 2>, acesso em maio de 2017.

MEURER, José Luiz. O trabalho de leitura crítica: recompondo representações, relações e identidades sociais. Ilha do desterro. Florianópolis. nº 38, p 155-171, jan./jun., 2000. 
O VALOR DE CADA UM. Disponível em

$<$ http://www.youtube.com/watch?v=ENofmMTOdw4>, acesso em 16 de junho de 2017.

SOARES, Angélica. Gêneros literários. São Paulo: Ática, 2007.

SOLÉ, Isabel. Estratégias de leitura. 6aed. Porto Alegre: Artmed, 1998.

\begin{abstract}
A AUTORA
Marise Rodrigues Guedes é mestra em Letras e especialista em Leitura e Produção textual pela Universidade Estadual de Santa Cruz - UESC. Possui graduação em Letras pela mesma Universidade. É Professora do Ensino Básico Técnico e Tecnológico de Línguas Portuguesa e Espanhola no Instituto Federal de Educação, Ciência e Tecnologia Baiano - IFBAIANO. Atualmente, coordena o Curso de Pós-graduação lato sensu em Leitura e Produção Textual Aplicadas à Educação de Jovens e Adultos do IF Baiano, campus Itapetinga. É membro do Grupo de Pesquisa Linguagem, Ensino e Identidade (UESC) e do Grupo de Pesquisa em Educação, Diversidade, Linguagens e Tecnologias (IFBAIANO).
\end{abstract}

\title{
E-mail: mariseguedess@hotmail.com
}

